\title{
A STUDY OF a-SiC/c-Si(n) ISOTYPE HETEROJUNCTIONS
}

\author{
N. GEORGOULAS, L. MAGAFAS, AND A. THANAILAKIS \\ Laboratory of Electrical and Electronic Materials Technology, Department of Electrical Engineering, \\ Democritus University of Thrace, 67100 Xanthi, Greece
}

(Received January 20, 1993; in final form May 3, 1993)

In the present work a study of the electrical properties of heterojunctions between rf sputtered amorphous silicon carbide (a-SiC) thin films and n-type crystalline silicon (c-Si) substrates is reported. The current-voltage (I-V) and capacitance-voltage (C-V) characteristics, as well as the temperature dependence of the current of a-SiC/c-Si(n) heterojunctions were measured. The I-V characteristics of a-SiC/ $\mathrm{c}-\mathrm{Si}(\mathrm{n})$ heterojunctions exhibit poor rectification properties, with a high reverse current, at higher temperatures $(T>250 \mathrm{~K})$, whereas good rectification properties are obtained at lower temperatures ( $\mathrm{T}$ $<250 \mathrm{~K})$. It was found that the a-SiC/c-Si(n) heterojunctions are isotype, suggesting that the conductivity of a-SiC is n-type. The temperature dependence of the current (from $185 \mathrm{~K}$ to $320 \mathrm{~K}$ ) showed that the majority carriers of $\mathrm{c}-\mathrm{Si}(\mathrm{n})$ (i.e. electrons) are transported from $\mathrm{c}-\mathrm{Si}(\mathrm{n})$ to a-SiC mainly by the thermionic emission mechanism, or by the drift-diffusion mechanism. From $\mathrm{C}-\mathrm{V}$ measurements of a-SiC/c-Si(n) heterojunctions the electron affinity of a-SiC was found to be $\mathrm{X}_{1}=4.20 \pm 0.04 \mathrm{eV}$. Finally, the a-SiC/ $\mathrm{c}-\mathrm{Si}(\mathrm{n})$ isotype heterojunctions are expected to be interesting devices as infrared detectors.

\section{INTRODUCTION}

Recently, extensive research work has been carried out on heterojunctions between amorphous silicon (a-Si), or amorphous germanium (a-Ge), and crystalline semiconductors ${ }^{1-6}$, because of their use in many semiconductor devices, such as metal-amorphous silicon FETs $\mathrm{s}^{7.8}$, thin film transistors ${ }^{9-11}$, heterojunction bipolar transistors ${ }^{12.13}$, and solar cells ${ }^{14.15}$. However, the physics of amorphous-crystalline heterojunctions is not clearly understood.

On the other hand, very little work has been done on the a-SiC/c-Si heterojunction $^{16.17}$, although a-SiC exhibits a series of important properties (e.g. wide optical band gap, photoluminescence, electroluminescence, mechanical strength), and c-Si is the most well known semiconductor material, so that the a$\mathrm{SiC} / \mathrm{c}-\mathrm{Si}$ heterojunction could be very useful in many semiconductor devices.

In the present work, studies of the electrical properties of $\mathrm{rf}$ sputtered a-SiC/c$\mathrm{Si}(\mathrm{n})$ heterojunction structures are presented, for the first time. The results were found to be consistent with those of our previous work on the a-SiC/c-Si(p) heterojunction ${ }^{16}$, suggesting that a-SiC exhibits conductivity of $n$-type, so that the heterojunction a-SiC/c-Si(n) is isotype. This type of heterojunction, could be a part of the structure a-SiC/c-Si(n)/c-Si(p), which is expected to be an interesting device for high efficiency solar cells. A similar structure of the form a-Si/c-Si(n)/ $\mathrm{c}-\mathrm{Si}(\mathrm{p})$ has also been proposed for high efficiency solar cells. ${ }^{18}$ 


\section{FABRICATION OF a-SiC/c-Si(n) HETEROJUNCTIONS}

a-SiC thin films, with a thickness of about $1 \mu \mathrm{m}$, were deposited by rf sputtering on n-type $\mathrm{Si}(5-10 \Omega \mathrm{cm})$ substrates, with ohmic contacts $(\mathrm{Al})$ at their back sides. The target used was SiC of constant composition (66 wt\% Si and $34 \mathrm{wt} \% \mathrm{C}$ ), $99.8 \%$ purity and $81 \mathrm{~cm}^{2}$ in area. The rf power was $250 \mathrm{~W}$ and the target-to-substrate distance was $5.5 \mathrm{~cm}$. The substrate temperature was $30^{\circ} \mathrm{C}$ and the sputtering chamber was evacuated below $5 \times 10^{-7}$ Torr before the introduction of argon. During deposition, the flow rate of argon was $20 \mathrm{sccm}$ and the pressure in the sputtering chamber $6 \mathrm{~m}$ Torr. Different metals $(\mathrm{Mg}, \mathrm{In}, \mathrm{Al}, \mathrm{Pd})$ of $0.785 \mathrm{~mm}^{2}$ in area were, subsequently, evaporated on the a-SiC thin films to form the front ohmic contacts.

\section{RESULTS AND DISCUSSION}

Figure 1 shows a typical structure of the a-SiC/c-Si(n) isotype heterojunctions (figure 1(a)), and its energy band diagram under thermal equilibrium (figure 1(b)), as well as under forward-bias conditions (figure 1(b)). This energy band diagram was calculated using Anderson's model ${ }^{19}$. The conductivity of a-SiC was considered to be n-type, as it was found in our earlier study ${ }^{16}$, and it has been confirmed by the present work. The subscripts 1 and 2 refer to a-SiC and to c-Si(n), respectively, so that $\mathrm{E}_{\mathrm{C} 1}, \mathrm{E}_{\mathrm{C} 2}$ are the edges of conduction bands, $\mathrm{E}_{\mathrm{V} 1}, \mathrm{E}_{\mathrm{V} 2}$ the edges of valence bands, $\delta_{1}, \delta_{2}$ the distances between the Fermi level and the corresponding conduction band edges, $E_{g 1}, E_{g 2}$ the energy band gaps, $V_{D 1}, V_{D 2}$ the partial diffusion potentials, $\Delta \mathrm{E}_{\mathrm{C}}, \Delta \mathrm{E}_{\mathrm{V}}$ the discontinuities of the conduction and valence bands, respectively, and $E_{F}$ the Fermi level under thermal equilibrium conditions. Under forward bias conditions the polarity is positive on the a-SiC side of the junction. As it is shown in figure 1(b), the deposition of a-SiC on c-Si(n) substrates leads to the creation of a small potential barrier. Electrons from the c-Si(n) side can surpass the potential barrier more easily than electrons from the a-SiC side, and thus, they contribute to the main current component through the heterojunction.

Figure 2 shows typical I-V characteristics of a-SiC/c-Si(n) isotype heterojunctions, measured at temperatures from $185 \mathrm{~K}$ up to $320 \mathrm{~K}$. These characteristics, at higher temperatures $(\mathrm{T}>250 \mathrm{~K})$, exhibit poor rectification properties, with a high reverse current (the ratio of forward current $\left(I_{F}\right)_{V=0.5}$ over the reverse current $\left(I_{R}\right)_{V=-1}$ at $T=295 \mathrm{~K}$ being equal to 14$)$, due to a relatively small conduction band barrier height $\left(\Delta E_{C}-q V_{D 1}\right)$, whereas good rectification properties are obtained at lower temperatures $(\mathrm{T}<250 \mathrm{~K})$, where the number of electrons in a$\mathrm{SiC}$ available to pass through the junction is greatly reduced (the ratio of $\left(\mathrm{I}_{\mathrm{F}}\right)_{\mathrm{V}=0.5}$ over $\left(I_{R}\right)_{V=-1}$ at $T=235 \mathrm{~K}$ being equal to 1000$)$. These results are in very good agreement with the experimental results obtained from isotype crystalline heterojunctions ${ }^{20-22}$. In contrast to a-SiC/c-Si(n) isotype heterojunctions, our previous study on a-SiC/c-Si(p) anisotype heterojunctions ${ }^{16}$ showed that their $\mathrm{I}-\mathrm{V}$ characteristics exhibit good rectification properties even for room temperature.

Figure 3 shows typical forward $\log \left(\mathrm{I}_{\mathrm{F}}\right)-\mathrm{V}$ characteristics of a-SiC/c-Si(n) heterojunctions, measured at different temperatures from $185 \mathrm{~K}$ up to $320 \mathrm{~K}$. After 
a-SiC/c-Si(n) HETEROJUNCTIONS
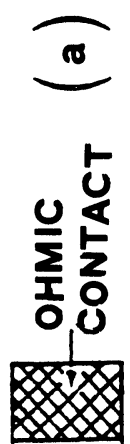

ए5

高

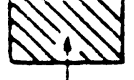

点
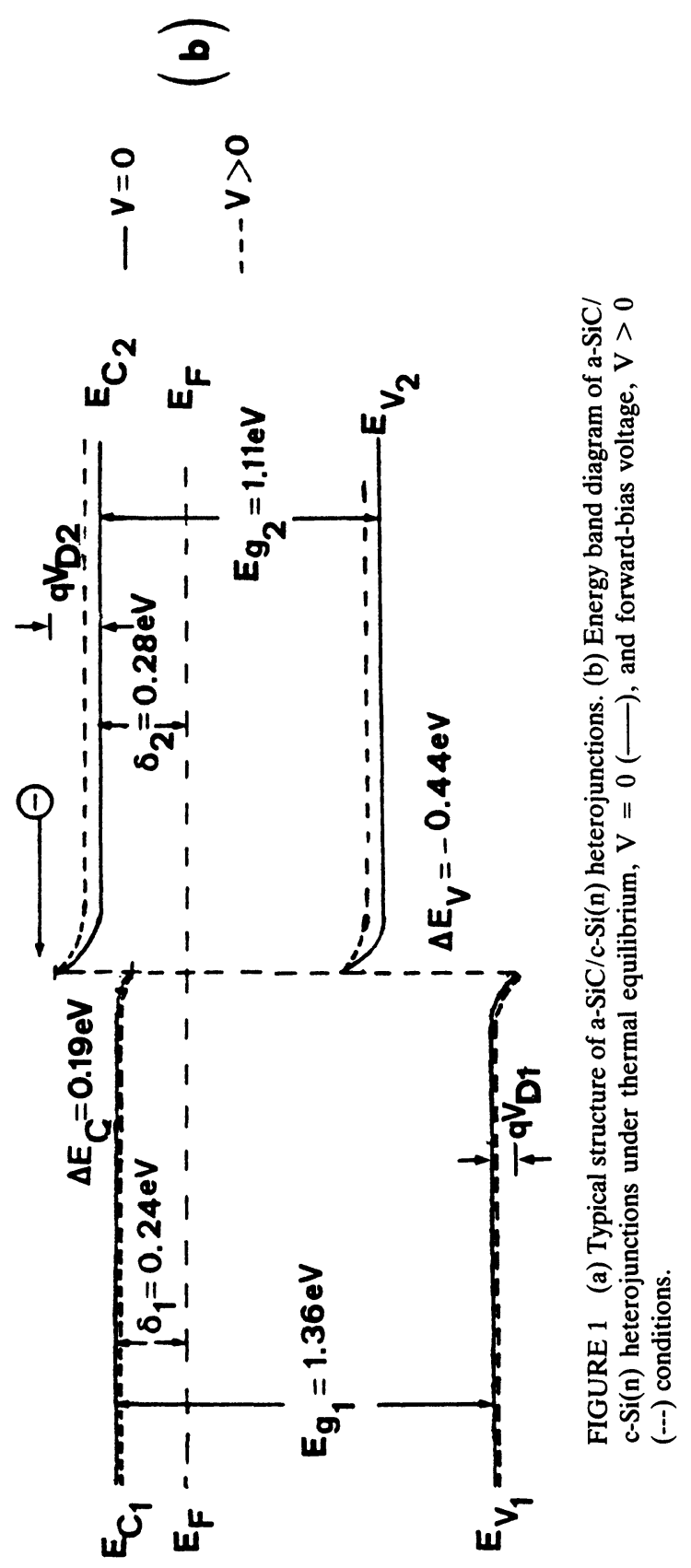


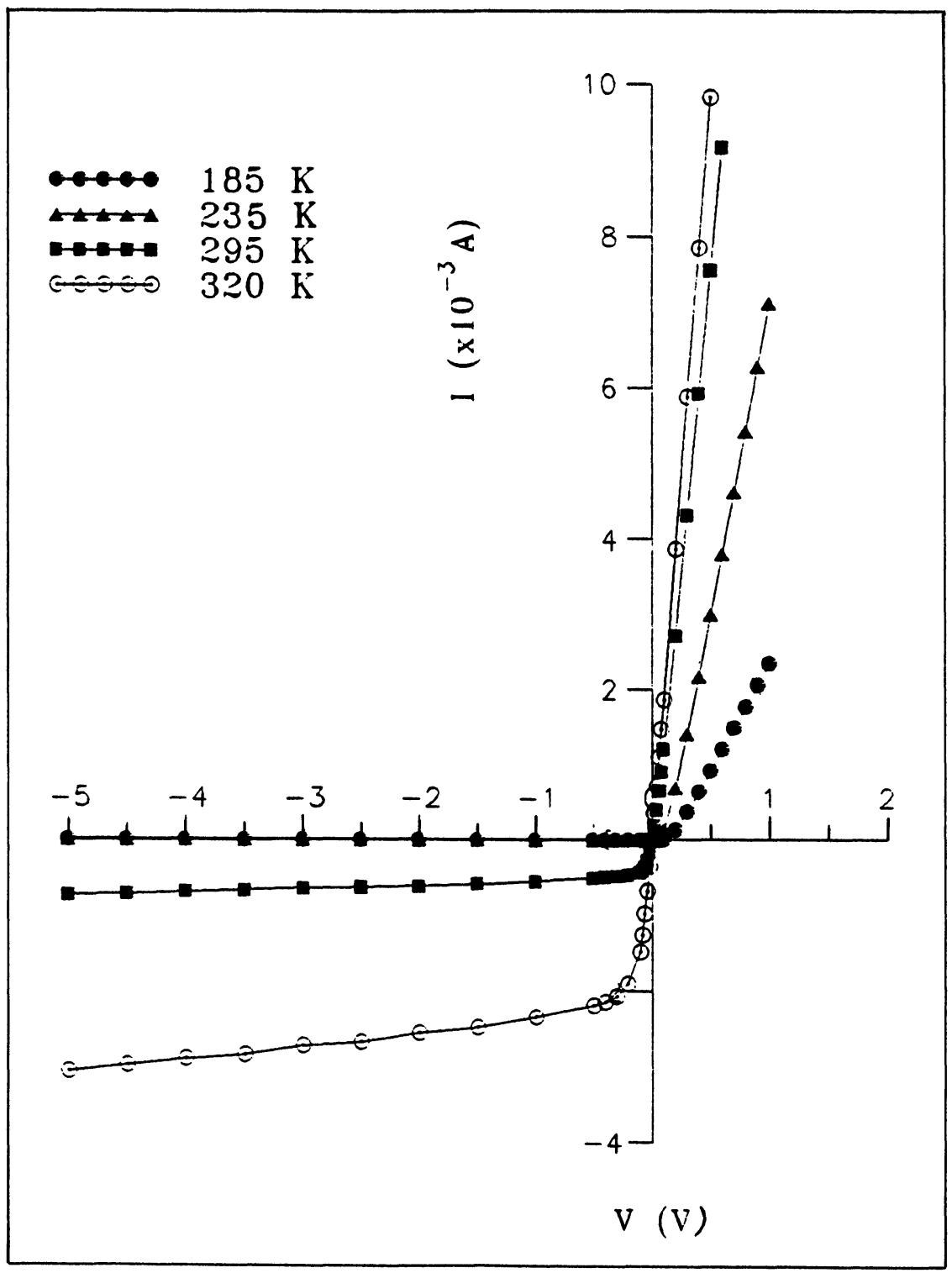

FIGURE 2 Typical current-voltage (I-V) characteristics of a-SiC/c-Si(n) heterojunctions at different temperatures (device area $=0.785 \mathrm{~mm}^{2}$ ).

correcting the series resistance, by subtracting from the applied voltage the voltage drop on the series resistance, all forward bias $I_{F}-V$ curves obey the relation ${ }^{20}$ :

$$
I_{F}=I_{s}\left[\exp \left(\frac{q V}{\eta k T}\right)-1\right]
$$




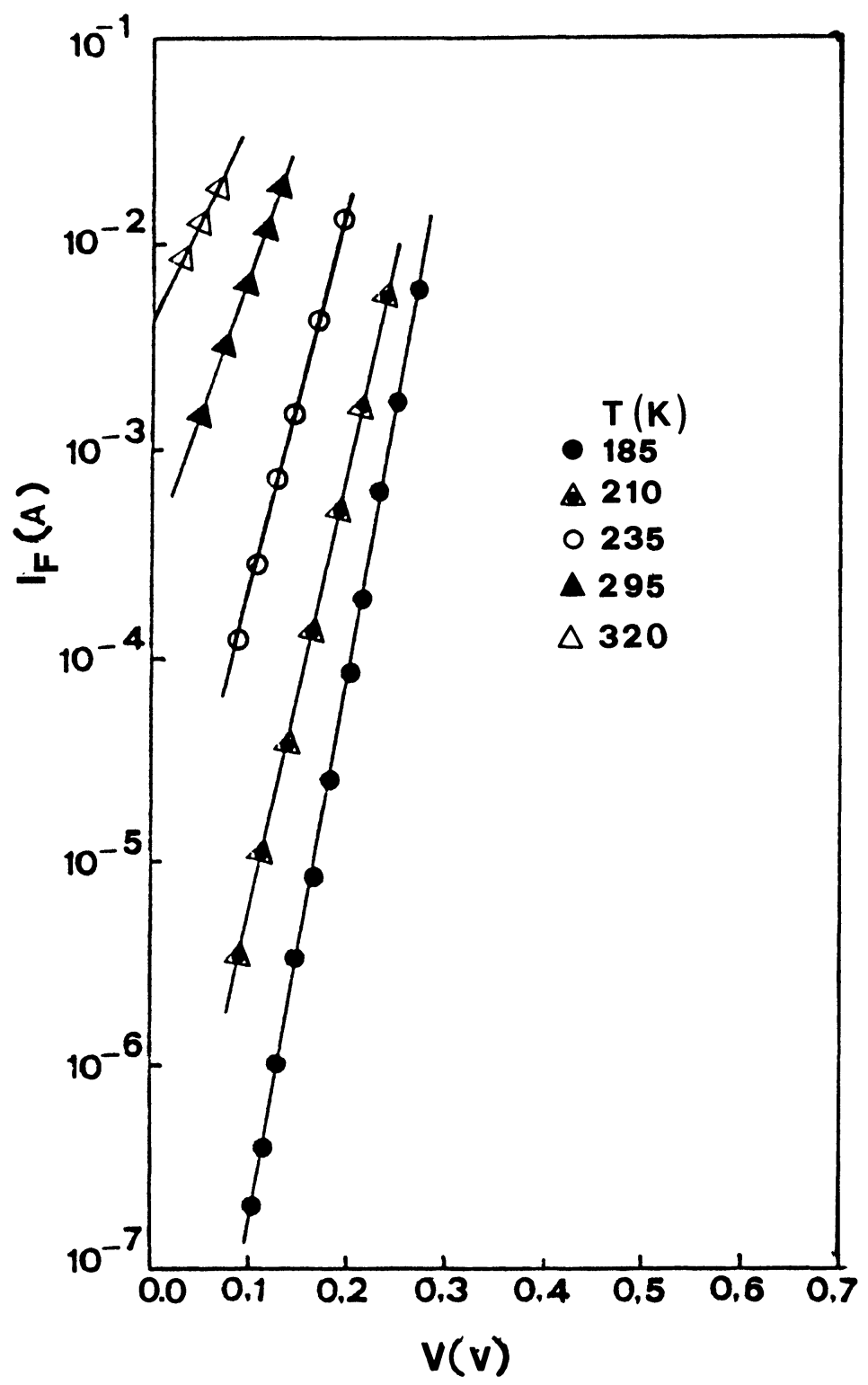

FIGURE 3 Typical forward current-voltage $\left(\log \left(I_{F}\right)-V\right)$ characteristics of a-SiC/c-Si(n) heterojunctions, at different temperatures (device area $=0.785 \mathrm{~mm}^{2}$ ).

or

$I_{F}=I_{s} \exp \left(\frac{q V}{\eta k T}\right), \quad$ for $V>\frac{3 k T}{q}$

where $I_{s}$ is the saturation current, $q$ the magnitude of electronic charge, $V$ the applied forward bias voltage, $\eta$ the ideality factor, $T$ the absolute temperature of 
measurements and $k$ Boltzmann's constant. From the $\log I_{F}-V$ plots the value of ideality factor was derived. It was found that $\eta=1.07 \pm 0.05$, for the whole temperature range studied. This value of $\eta$ indicates that the majority carriers from c-Si(n) (i.e. electrons) are transported to a-SiC, either by the thermionic emission, or by the drift-diffusion mechanism ${ }^{20}$.

In the case of thermionic mission, the saturation current $I_{s}$ has the following temperature dependence ${ }^{20}$ :

$I_{s}=A^{1 / 2} \exp \left(\frac{B}{k T}\right)$

whereas in the case of drift-diffusion, the saturation current has a temperature dependence of the form ${ }^{20}$

$I_{s}=\operatorname{Cexp}\left(\frac{D}{k T}\right)$

where $\mathrm{A}, \mathrm{B}, \mathrm{D}$ are constants, and $\mathrm{C}$ a weakly temperature dependent quantity.

Figure 4 shows the typical characteristic of $\log I_{s}$ and $\log \left(I_{s} / T^{1 / 2}\right)$, as a function of $10^{3} / \mathrm{T}$. According to eqs (2) and (3), a linear relationship between $\log \left(\mathrm{I}_{\mathrm{s}} / \mathrm{T}^{1 / 2}\right)$ and $10^{3} / \mathrm{T}$ is expected for the case where electrons are transported from c-Si(n) to a-SiC by the thermal emission mechanism, whereas a linear relationship is expected between $\log \mathrm{I}_{\mathrm{s}}$, and $10^{3} / \mathrm{T}$ for the case where drift-diffusion is the dominant transport mechanism. It is clear from figure 4 , that a linear relationship is obtained in both cases, suggesting that it is very difficult to distinguish the dominant transport mechanism, between the thermionic emission and drift-diffusion mechanisms, from the I-V measurements in different temperatures. So, both thermionic emission and drift-diffusion transport mechanisms, may be considered to contribute to the current transport, as it has been suggested by R. J. Schuelke and M. S. Lundstrom ${ }^{22}$, for abrupt isotype crystalline heterojunctions.

In a previous work ${ }^{16}$, we have found that the effective density of localized gap states in a-SiC is $\mathrm{N}_{1} \cong 5 \times 10^{17} \mathrm{~cm}^{-3}$, and a comparison between $\mathrm{N}_{1}$ and the density of donor impurities, $\mathrm{N}_{2}$, in c-Si, with a resistivity equal to $10 \Omega \mathrm{cm}$, indicates that the a-SiC/c-Si(n) isotype heterojunction should be a one sided junction. The differential capacitance, $\mathrm{C}$, as a function of the applied bias voltage, $\mathrm{V}$, in one sided abrupt isotype heterojunctions, is given by the relation ${ }^{19,20}$ :

$$
\frac{\mathrm{C}}{\mathrm{s}}=\left(\frac{\mathrm{q} \varepsilon_{0} \varepsilon_{2} \mathrm{~N}_{2}}{2\left(\mathrm{~V}_{\mathrm{D}}-\mathrm{V}\right)}\right)^{1 / 2}
$$

where $\varepsilon_{2}$ is the dielectric constant of $\mathrm{c}-\mathrm{Si}(\mathrm{n}), \varepsilon_{0}$ the free space permittivity, $\mathrm{s}$ the area of the heterojunction and $V_{D}$ the diffusion potential.

In order to calculate the energy band diagram and to ensure the abruptness of a-SiC/c-S(n) isotype heterojunctions, differential capacitance-voltage measurements were carried out. Figure 5 shows a typical experimental $\mathrm{C}-\mathrm{V}$ characteristic 


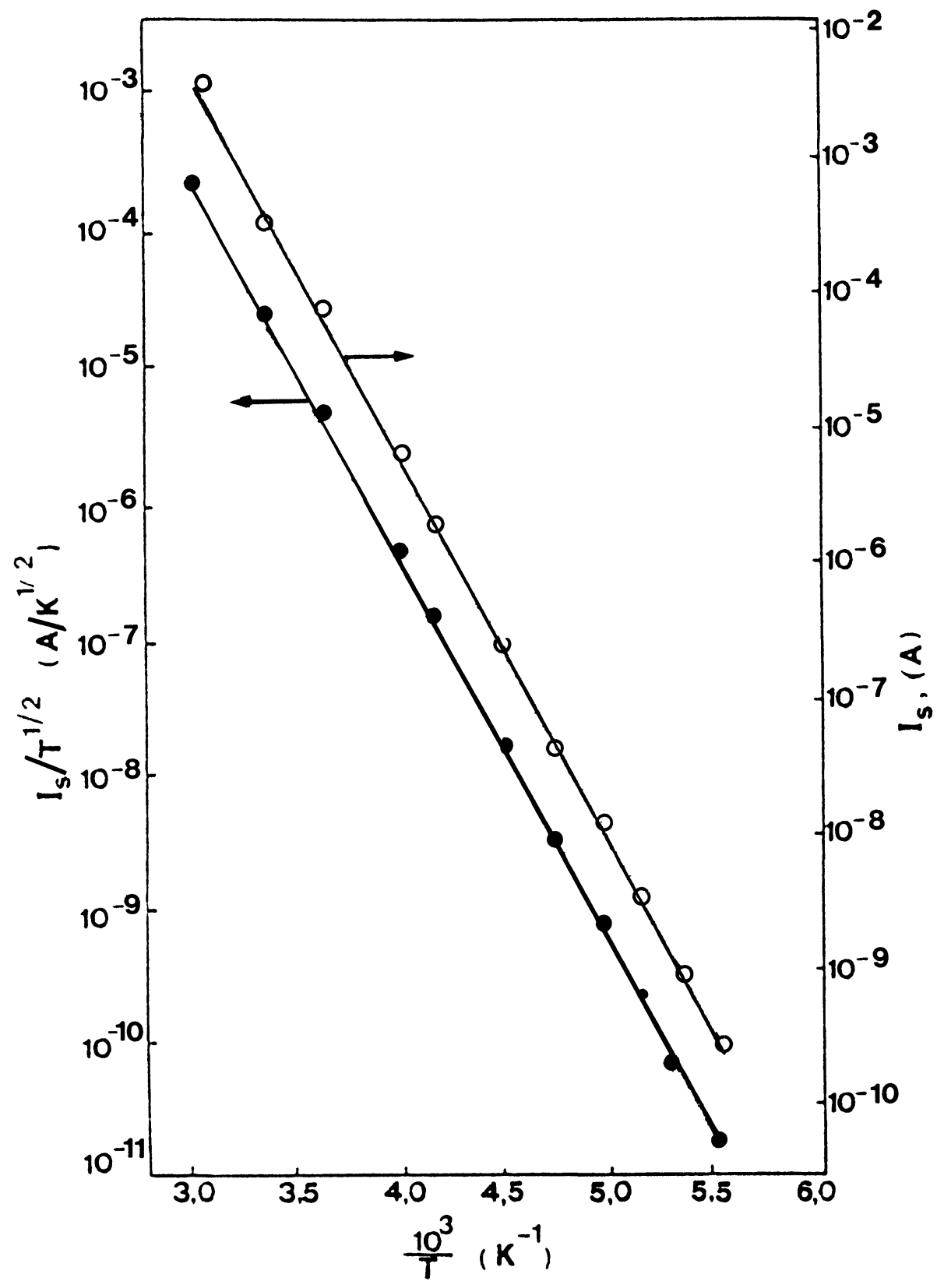

FIGURE $4 \log \left(I_{\mathrm{s}} / \mathrm{T}^{1 / 2}\right)$ and $\log \mathrm{I}_{\mathrm{s}}$ of a-SiC/c-Si(n) heterojunctions as a function of $10^{3} / \mathrm{T}$ (device area $=0.785 \mathrm{~mm}^{2}$ ). 


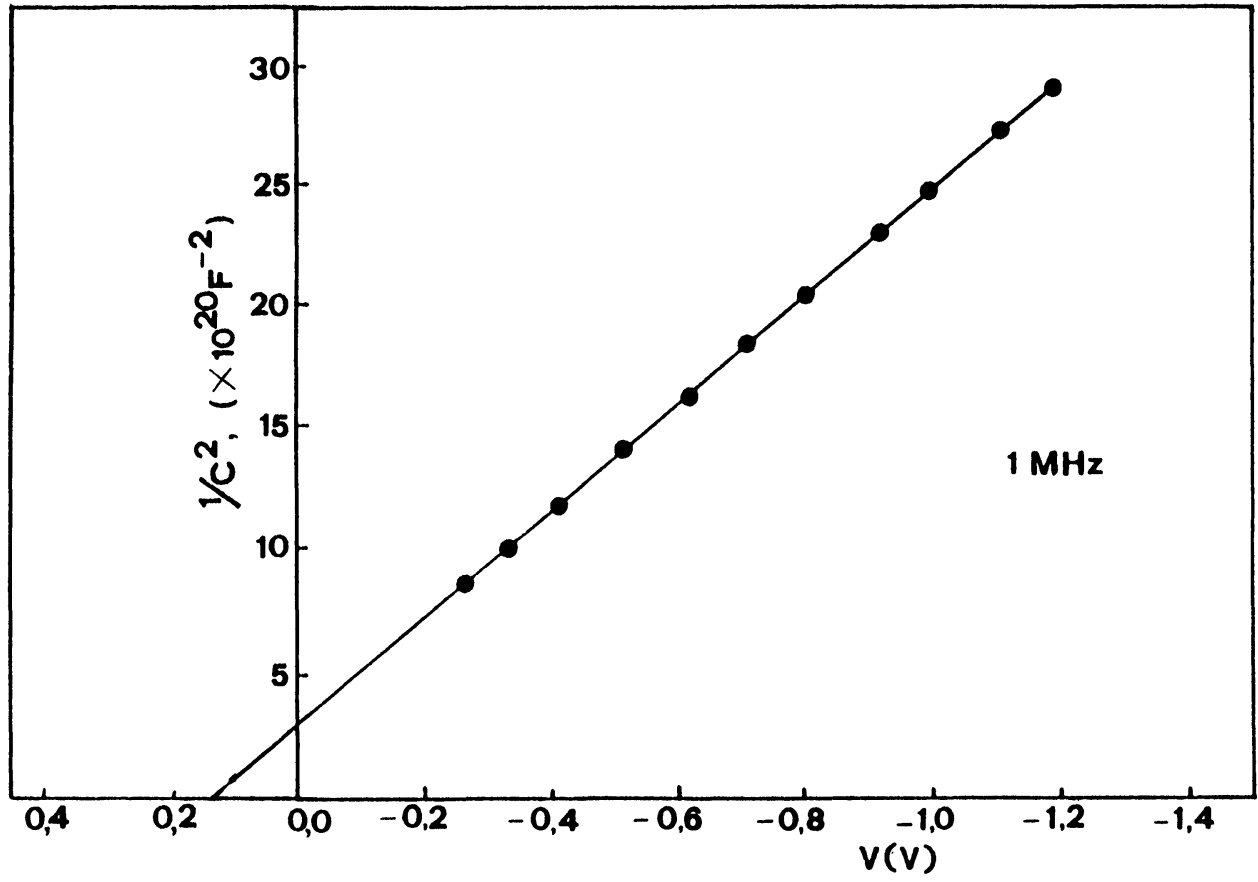

FIGURE 5 A typical room temperature capacitance-voltage (C-V) characteristic of a-SiC/c-Si(n) heterojunctions, measured at $1 \mathrm{MHz}\left(\right.$ device area $=0.785 \mathrm{~mm}^{2}$ ).

of a-SiC/c-Si(n) isotype heterojunction, measured at $1 \mathrm{MHz}$. It is clear from this figure, that the plot of $1 / \mathrm{C}^{2}$ versus bias voltage, $\mathrm{V}$, is a straight line. Taking into account that interdiffusion is very unlikely, since the deposition of a-SiC thin films takes place at a substrate temperature of $30^{\circ} \mathrm{C}$, this linear dependence of $1 / \mathrm{C}^{2}$ on $\mathrm{V}$ indicates that the a-SiC/c-Si(n) isotype heterojunction is abrupt. A similar result has also been obtained from the $\mathrm{C}-\mathrm{V}$ measurements of a-SiC/c-Si(p) heterojunctions ${ }^{16}$. From the slope of $1 / \mathrm{C}^{2}-\mathrm{V}$ plot, the density of donor impurities in $\mathrm{c}-\mathrm{Si}(\mathrm{n})$ was estimated, using eqn (4), and it was found to be $N_{2}=5 \times 10^{14} \mathrm{~cm}^{-3}$. This is in agreement with the theoretical value obtained from the resistivity of $\mathrm{Si}$ substrates, indicating that the a-SiC/c-Si(n) isotype heterojunction is a one sided junction, whose depletion region is mainly extended within the c-Si(n) substrate.

From the same plot of figure 5 , the value of diffusion potential, $V_{D}$, was obtained from the intercept of this straight line with the voltage axis, taking into account the Gummel correction. This was found to be $V_{D}=0.15 \pm 0.04 \mathrm{eV}$, irrespective of the front metal electrode used, indicating that the contact between the front metal and a-SiC behaves as an ohmic one, as it was found in our earlier study ${ }^{16}$. Using this value of $V_{D}$ and the relations ${ }^{19.20:}$

$$
\begin{aligned}
& \Delta \mathrm{E}_{\mathrm{C}}=\mathrm{qV}_{\mathrm{D}}-\delta_{1}+\delta_{2} \\
& \Delta \mathrm{E}_{\mathrm{V}}=\left(\mathrm{E}_{\mathrm{g} 2}-\mathrm{E}_{\mathrm{g} 1}\right)-\Delta \mathrm{E}_{\mathrm{C}} \\
& \Delta \mathrm{E}_{\mathrm{C}}=\mathrm{X}_{1}-\mathrm{X}_{2}
\end{aligned}
$$


the quantities $\Delta \mathrm{E}_{\mathrm{C}}$ and $\Delta \mathrm{E}_{\mathrm{V}}$ were calculated, for the first time, and were found to be $\Delta \mathrm{E}_{\mathrm{C}}=0.19 \pm 0.04 \mathrm{eV}$ and $\Delta \mathrm{E}_{\mathrm{V}}=-0.44 \pm 0.04 \mathrm{eV}$. From the value of $\Delta \mathrm{E}_{\mathrm{C}}$, the electron affinity, $X_{1}$, of a-SiC was calculated, using eqn (7) where $X_{2}$ is the known electron affinity of c-Si(n). The value of $X_{1}$ obtained in this work is $X_{1}=4.20 \pm 0.04$ $\mathrm{eV}$, which is, within experimental error, in agreement with the value of $\mathrm{X}_{1}$ obtained from the study of a-SiC/c-Si(p) anisotype heterojunctions ${ }^{16}$. This result confirms that the conductivity of a-SiC is n-type, and that the a-SiC/c-Si(n) heterojunction is isotype.

Finally, the small conduction band barrier height $\left(\Delta E_{C}-V_{D 1} \cong 0.18 \mathrm{eV}\right)$ of the a-SiC/c-Si(n) junction leads to the conclusion that these isotype heterojunctions would be interesting devices as infrared detectors for wavelengths $\lambda \leq 6.8 \mu \mathrm{m}$. This is supported by the fact that the absorption coefficient of the free conduction band carriers in a-SiC, given by the relation ${ }^{23}$ :

$\alpha \propto \frac{\mathrm{N}_{1} \lambda^{2}}{\mu}$

is expected to be relatively high, because of the small value of electron mobility. $(\mu$ $\leq 0.1 \mathrm{~cm}^{2} / \mathrm{V} . \mathrm{s}$ ) in amorphous semiconductors ${ }^{24}$.

\section{CONCLUSIONS}

The present study of the electrical properties of a-SiC/c-Si(n) heterojunctions leads to the following conclusions:

a) The I-V characteristics of a-SiC/c-Si(n) heterojunctions exhibit poor rectification properties, with high reverse, currents at higher temperatures $(\mathrm{T}>250 \mathrm{~K})$, whereas good rectification properties are obtained at lower temperatures $(\mathrm{T}<250 \mathrm{~K})$.

b) The a-SiC/c-Si(n) heterojunction was found to be isotype, suggesting that the conductivity of a-SiC is n-type.

c) The I-V characteristics of a-SiC/c-Si(n) heterojunctions at different temperatures, from $185 \mathrm{~K}$ to $320 \mathrm{~K}$, showed that the majority carriers of c-Si(n), (i.e. electrons) are transported from $\mathrm{c}-\mathrm{Si}(\mathrm{n})$ to a-SiC, mainly, by the thermionic emission mechanism, and or the drift-diffusion mechanism.

d) From $\mathrm{C}-\mathrm{V}$ measurements of a-SiC/c-Si(n) heterojunctions, the electron affinity of a-SiC was obtained, and it was found to be $\mathrm{X}_{1}=4.20 \pm 0.04 \mathrm{eV}$. This value of $\mathrm{X}_{1}$ is, within experimental error, in agreement with that we have obtained from studies of a-SiC/c-Si(p) anisotype heterojunctions.

e) Finally, the a-SiC/c-Si(n) isotype heterojunctions are expected to be interesting devices as infrared detectors.

\section{REFERENCES}

1. H. Matsuura, T. Okuno, H. Okushi and K. Tanaka, "Electrical properties of n-amorphous/pcrystalline silicon heterojunctions," J. Appl. Phys. 55, 1012 (1983).

2. H. Mimura, and Y. Hatanaka, "Optoelectrical properties of amorphous/crystalline silicon heterojunctions," App. Phys. Lett. 45, p. 452 (1984).

3. E.S. Yang, D.K. Yang, Q.H. Hua and G.S. Yang, "Tunneling in a metal-semiconductor-semiconductor thin film diode," Solid-State Electronics 29, p. 355 (1986).

4. A.I. Sambell and J. Wood, "Modification of GaAs Schottky barriers using a-Si:H interfacial layers," IEEE Electron Device Lett. 11, p. 385 (1990). 
5. J.J. Mares, J. Kristofik and V. Smid, "Transport properties of a-Ge/c-GaAs heterojunctions, Proc. Int. Conf. Amorphous Semiconductors, Bucharest 1982," Central Institute of Physics, Bucharest 1982, p. 219.

6. N.P. Sinha and M. Misra, "Junction between amorphous germanium and monocrystal Si," Solid State Electronics 26, p. 1177 (1983).

7. M. Susuki, K. Murase, N. Kato, M. Togashi and M. Hirayama, "Advances of Metallic-AmorphousSilicon-Gate FETs in GaAs LSI Applications," IEEE Trans. Electron Devices 33, p. 919 (1986).

8. M. Sakaue, K. Murase and Y. Amemiya, "Self-Aligned Half-Micrometer Silicon MASFET's with Metallic Amorphous Silicon Gate," IEEE Trans. Electron Devices 33, p. 988 (1986).

9. H.F. Bare and G. Neudeck, "Ion Implanted Contacts to a-Si:H Thin-Film Transistors," IEEE Electron Device Lett. 7, p. 431 (1986).

10. Z.W. Manookian and J .B. Wilson, "Interfacial problems in preparing a-Si:H FETs," IEE Proc. 133, Pt I, p. 153 (1986).

11. M.K. Hatalis and D.W. Greve, "High-Performance Thin-Film Transistors in Low-Temperature Crystallized LPCVD Amorphous Silicon Films," IEEE Electron Device Lett. 8, p. 361 (1987).

12. O.P. Bonnand and P. Victorovitch, "Modelling of a new high current gain bipolar transistor with n-doped hydrogenated silicon emitter," IEE Proc. 132, Pt I, p. 431 (1985).

13. Y.S. Wang, X.M. Zhang, W.W. Sheng and X.W. Wang, "Amorphous-Si Emitter Heterojunction UHF Transistors for Handy Transmitter," IEEE Electron Device Lett. 11, p. 187 (1990).

14. M.M. Rahman and S. Furukawa, "Amorphous/crystalline heterostructures as a novel approach to fabrication of solar cells," Electron Lett. 20, p. 57 (1984).

15. Y. Hamakawa, K. Fujimoto, K. Okuda, Y. Kashima, S. Nonomura, H. Okamoto, X. Kashima, S. Nonomura, and H. Okamoto, "New types of high efficiency solar cells based on a-Si," Appl. Phys. Lett. 43, p. 644 (1983).

16. L. Magafas, N. Georgoulas and A. Thanailakis, "Electrical properties of a-SiC/c-Si(p) heterojunctions," Semiconductor Science and Technology 7, p. 1363 (1992).

17. D. Dimitriades, N. Georgoulas, and A. Thanailakis, "New a-SiC, optically controlled, thyristorlike switch," Electronics Lett. 28, p. 1622 (1992).

18. F. Rubinelli, S. Albornoz and R. Buirtzago, "Amorphous-Crystalline isotype heterojunction: Electrostatic potential distribution and C(V) curves," Solid State Electronics 28, p. 741 (1985).

19. A.G. Milnes and D.L. Feuht, "Heterojunction and Metal/Semiconductor Junctions," Academic, New York (1972).

20. B.L. Sharma and R.K. Purohit, "Semiconductor Heterojunctions," Int. Series of Monographs in the Science of Solid State, Vol. 5, Pergamon, New York (1974).

21. S.R. Forrest and O.K. Kim, "An n- $\operatorname{In}_{0.53} \mathrm{Ga}_{0.47} \mathrm{As} / \mathrm{n}$-InP rectifier," J. Appl. Phys. 52, p. 5838 (1981).

22. R.J. Schuelke and M.S. Lundstrom, "Thermionic Emission-Diffusion theory of isotype heterojunctions," Solid-State Electronics 27, p. 1111 (1984).

23. H.F. Wolf, "Silicon semiconductor data," Pergamon Press, New York (1969).

24. M.H. Brodsky (ed.) “Amorphous Semiconductors” Springer-Verlag, Berlin, 2nd Ed. (1985). 

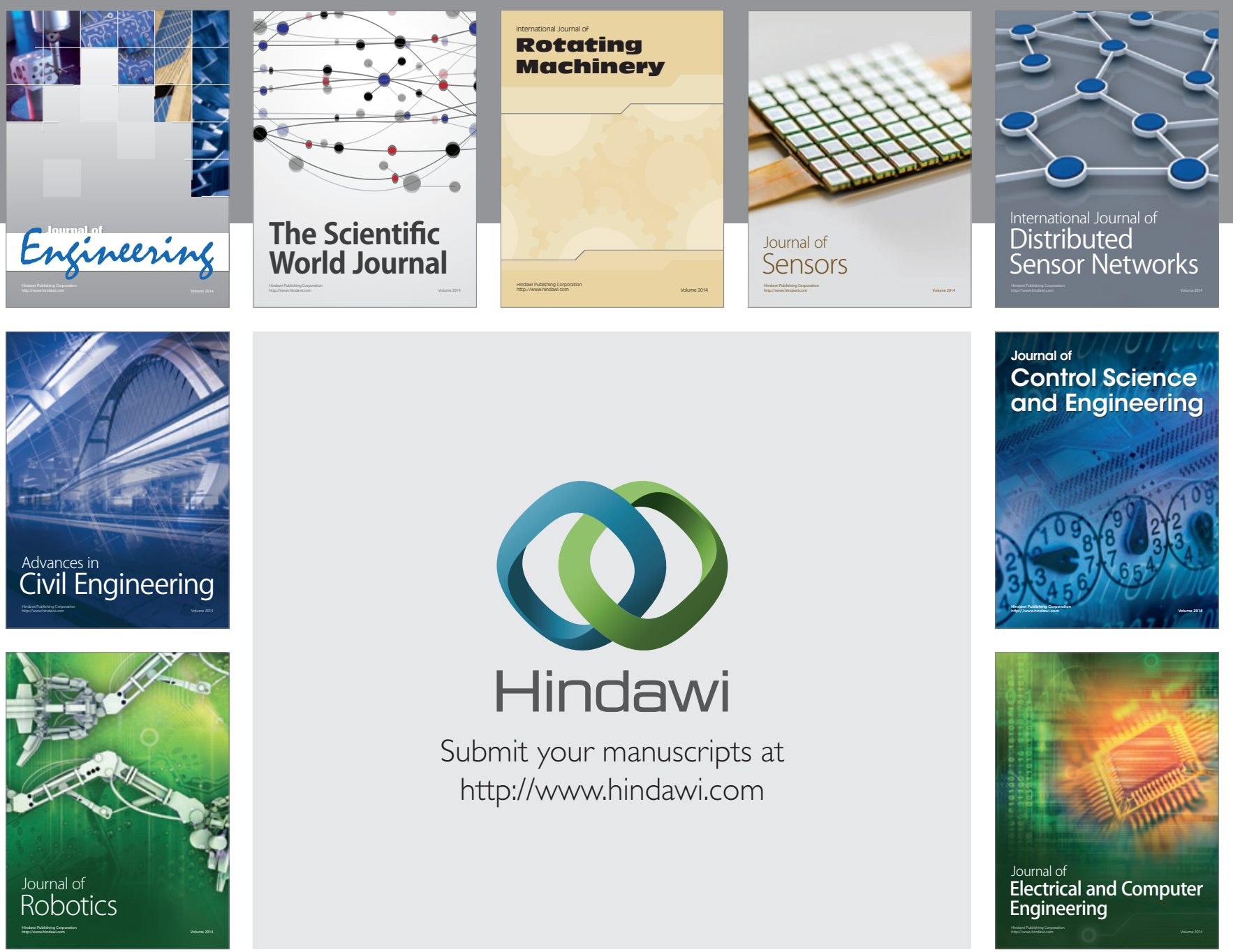

Submit your manuscripts at

http://www.hindawi.com
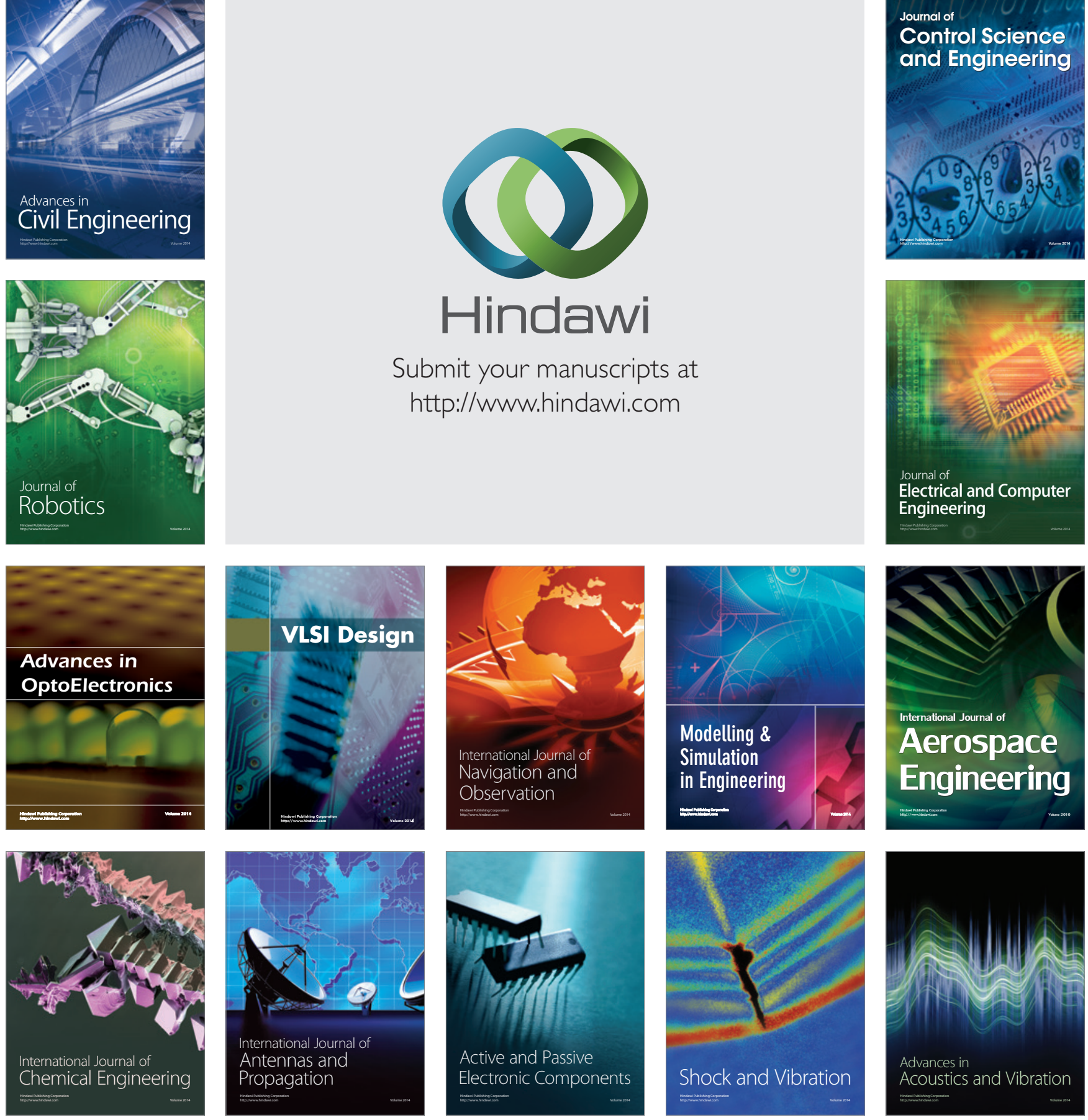